Copyright (C) 2021 University of Bucharest Printed in Romania. All rights reserved

ISSN print: $1224-5984$

ISSN online: $2248-3942$
Rom Biotechnol Lett. 2021; 26(6): 3114-3119

doi: $10.25083 / \mathrm{rbl} / 26.6 / 3114-3119$

Received for publication, October, 23, 2021

Accepted, November, 9, 2021

Original paper

\title{
Studying some neuroprotective effects of Calotropis procera extracts against scopolamine- induced neuropschiatric comorbidities in a rodent model of epilepsy
}

\author{
PROSPER T. KINDA ${ }^{1,2}$, SAMSON GUENNE ${ }^{1}$, BASILE TINDANO ${ }^{3}$, NOUFOU \\ OUEDRAOGO $^{4}$, NABÉRÉ OUATTARA ${ }^{1,5}$, PATRICE ZERBO ${ }^{6}$, RALUCA ELENA \\ DUTA $^{7}$, ALIN CIOBICA ${ }^{\mathbf{7 , 8 , 9}}$, MARTIN KIENDREBEOGO ${ }^{1}$. \\ ${ }^{1}$ Laboratory of Applied Biochemistry and Chemistry (LA.BIO.C.A), University Joseph KI-ZERBO, 03 P.O. Box: 7021 \\ Ouagadougou 03, Burkina Faso. \\ ${ }^{2}$ Laboratory of Forensic Sciences, General Direction of National Police, 01 P.O. Box: 22 Ouagadougou 01, Burkina Faso. \\ ${ }^{3}$ Laboratory of Animal Physiology, University Joseph KI-ZERBO, 03 P.O. Box: 7021 Ouagadougou 03, Burkina Faso \\ ${ }^{4}$ Institute for Research in Health Sciences (IRSS/CNRST), Department of Medicine and Traditional Pharmacopoeia \\ (MEPHATRA-PH), 03 P.O. Box: 7192 Ouagadougou 03, Burkina Faso. \\ ${ }^{5}$ University of Dedougou, BP 147, Burkina Faso. \\ ${ }^{6}$ Laboratoire de Biologie et écologie végétale, Université Joseph KI-ZERBO, 03 BP 7021 Ouagadougou 03, Burkina Faso \\ ${ }^{7}$ Department of Biology, Faculty of Biology, Alexandru Ioan Cuza University, B dul Carol I, no 11, Iasi, Romania \\ ${ }^{8}$ Academy of Romanian Scientists, Splaiul Independentei nr. 54, sector 5, 050094 Bucuresti, Romania \\ ${ }^{9}$ Center of Biomedical Research, Romanian Academy, Iasi, B du l Carol I, no 8, Romania
}

\begin{abstract}
Many plants are largely used in alternative medicine of Burkina Faso for neuropsychiatric disorders treatment. However, their neuro-pharmacological properties are less evaluated through scientific studies. The present study aims to evaluate the neuroprotective effect of Calotropis procera leaves and root-bark aqueous extract, focusing on a scopolamine-induced model of epilepsy in rodents. In this study, we evaluated this plant extracts possible protective effects on the central nervous system, through the behavioral tests and the enzymes activity assays. Thus, elevated plus-maze test and Y-maze task were used to evaluate animals behavioral and UV/visible spectrophotometer methods were used to evaluate the enzyme's activities in brain's supernatant. Our results are showing no significant protective effects of leaves extract, but it revealed a significant neuroprotective effect of root-bark aqueous extract, as well as in the behavioral tests and the brain's oxidative enzymes specific activity evaluation. Indeed, anti-amnesic and anxiolytic activities were observed through Y maze task and elevated plus maze tests for the groups of animals receiving root-bark extract (100 mg/kg b.w.). In these test, inhibition of disturbances of Time spent in Open Arms, Spontaneous Alternation, and Transfer Latency induced after scopolamine administration were recorded with animals received root-bark extract. Likewise, the superoxide dismutase and catalase activity disturbance induced by scopolamine were also inhibited in root-bark extract pre-administered group. Thus, our study provides biochemical and neuro-pharmacological data for traditional use of C. procera for neuropsychiatric disorders treatment, including scopolamine-induced epilepsy symptoms (mainly referring to the psychiatric comorbidities of this disorder).
\end{abstract}

Keywords Calotropis procera, anti-amnesic, antioxidant, behavioral; neuroprotective

To cite this article: KINDA PT, GUENNE S, TINDANO B, OUEDRAOGO N, OUATTARA N, ZERBOP, DUTA RE, ALIN CIOBICA A, KIENDREBEOGOM. Studying some neuroprotective effects of Calotropis procera extracts against scopolamine- induced neuropschiatric comorbidities in a rodent model of epilepsy. Rom Biotechnol Lett. 2021; 26(6): 3114-3119. DOI: 10.25083/rbl/26.6/3114-3119. 


\section{Introduction}

Medicinal plants are diversely used in traditional therapy in the world to treat various diseases. These plants are very important for alternative medicine in Burkina Faso because most of rural populations use them to ensure their primary healthcare [1]. The neuropsychiatric diseases which are characterized by anomalies of the thought, emotions, behavior and relationship with others, increasingly affect population in Burkina Faso [2]. Epilepsy is reported as one of the most common neurological disorders through the world. It affects around $1 \%$ of people in the world, including $80 \%$ in developing countries with a high prevalence in Africa $[3,4]$. According to the previous studies, most symptoms of this disorders include anxiety, depression, amnesia and oxidative damage $[5,6,7]$.

Calotropis procera is one of species of Asclepiadaceae family, which is reported to have therapeutic potential. This plant is used in traditional medicine to treat many diseases such as epilepsy, madness, hallucination, Insomnia, nerves diseases, otitis, tumors, drepanocytosis and liver diseases $[8,9,10]$. This plant is widely found in urban and rural areas and it is reported to contain important natural substances such as cardenolides (calotropin, calactin, uscharin), alkaloids ( $\alpha$ amyrine, $\beta$-amyrine), phenolic acid (ellagic, chlorogenic, caffeic and coumaric acids) and flavonoids (rutin, quercetin, kaempferol) $[8,11,12]$. Some of these chemical contents are well known to act on the nervous system $[13,14]$.

Scopolamine was previously used, besides its amnesic effects $[15,16,17,18,19]$, on inducing some epilepsy-like manifestations in rodents [20,21,22,23].

Thus, in the present study, based on the aspects mentioned above, we decided to Study the possible neuroprotective effects of Calotropis procera extracts against scopolamineinduced neuropschiatric comorbidities in a rodent model of epilepsy.

\section{Materials and Methods}

\section{Plant collection and preparation of extracts}

Calotropis procera leaves and root-bark were collected in Gampela, a village from central area of Burkina Faso. Plant was identified by botanists of the Plants Department of University Joseph Ki-ZERBO/Burkina Faso. Voucher specimens were deposited at the herbarium of this university having the identity number 16972 .

Twenty-five grams $(25 \mathrm{~g})$ of dried powder were extracted with $500 \mathrm{~mL}$ of distilled water at $100^{\circ} \mathrm{C}$ for 30 min. It was filtered using muslin cloth and centrifuged at $4000 \mathrm{rpm}$ for $10 \mathrm{~min}$. The supernatant was collected and lyophilized to dryness. The residue was weighed to obtain the extracted yield and it was kept at $4{ }^{\circ} \mathrm{C}$.

\section{Chemical}

Scopolamine, monobasic sodium phosphate $\left(\mathrm{NaH}_{2} \mathrm{PO}_{4}\right)$, dibasic sodium phosphate (Na2HPO4), ethylenediamine tetraacetic acid (EDTA), all solvents were analytical grades and purchased from Sigma-Aldrich (Germany). Diazepam was purchased from a local pharmacy.

\section{Experimental animals}

Wistar rats weighing $340 \pm 8 \mathrm{~g}$ were used. They were obtained from the animal house of University Joseph KIZerbo, and housed for a week under controlled conditions for acclimatization before the experiments. Animals were kept in plastic cages under identical animal house conditions and provided with standard pellet and water ad libitum. Twelve-hour light and dark alternate cycles (started at 6:00 a.m.) were provided, temperature was maintained at $22 \pm 3{ }^{\circ} \mathrm{C}$ and relative humidity was $50 \pm$ $10 \%$. Rats were treated in accordance with the guidelines of animal bioethics from the Act on Animal Experimentation and Animal Health and Welfare Act from Burkina Faso (Ethics committee acceptance CE-UOI2018-03) and all procedures were in compliance with the European Council Directive of 24 November 1986 (86/609/EEC). All evaluations were performed between 9 a.m. and 4 p.m.

\section{Drug administrations}

This study was conducted according to previously described method [24]. Drugs were daily prepared and administered by oral route during 14 consecutive days. The rats were randomized into five groups $(n=6)$. The $1^{\text {st }}$ group (Control) and the $2^{\text {nd }}$ group $(\mathrm{Sco})$ received saline $(\mathrm{NaCl}$ $0.9 \%)$. The group $3(\mathrm{CpL}+\mathrm{Sco})$ and $4(\mathrm{CpR}+\mathrm{Sco})$ received respectively $C$. procera leaves extract and root-bark extract $(100 \mathrm{mg} / \mathrm{kg})$. The last group (Dzp+Sco) received diazepam $(1,5 \mathrm{mg} / \mathrm{kg})$. The $14^{\text {th }}$ day, all groups excepted control received scopolamine hydrobromide $(0,7 \mathrm{mg} / \mathrm{kg}$, intraperitoneal route) $1 \mathrm{~h}$ after drug administration. Behavioral tests were performed 30 min after Scopolamine administration. Then, the anxiolytic, anti-amnesic and antioxidant effects of extracts were estimated.

\section{The anxiolytic evaluation}

\section{Elevated plus-maze test}

Resting on the natural fear of rodents on height and open spaces, the elevated plus-maze is a general search tool used for the neurobiological evaluation of drugs such as anxiety, exploration, motor [25]. This test was used in the present study to evaluate anxiety effect of extracts. The plus-maze consists of four arms, $49 \mathrm{~cm}$ long and $10 \mathrm{~cm}$ wide, elevated $50 \mathrm{~cm}$ above the ground. Two arms were enclosed by walls $30 \mathrm{~cm}$ high and the other two arms were exposed. Rats were individually placed at the juncture of arms and time spent on the open arms was recorded during $5 \mathrm{~min}$. Time spent in the closed arms is an index of anxiety.

\section{The anti-amnesic evaluation}

\section{Elevated plus-maze test}

A second model of Elevated plus-maze test was used to evaluate memory according to procedure previously described [26]. The used elevated plus maze consisted of two open arms $(49 \mathrm{~cm} \times 10 \mathrm{~cm})$ and two covered arms $(49 \mathrm{~cm} \times 10 \mathrm{~cm} \times 30 \mathrm{~cm})$, elevated to a height of $50 \mathrm{~cm}$ from the floor. On the first day, each rat was placed at the end of an open arm, facing away from the central platform. Transfer latency (TL) was defined as the time taken by the animal to move from the open arm into one of the covered arms with all its four legs. TL was recorded on the first day (i.e., $14^{\text {th }}$ day of drug administration) for each animal. The rat was allowed to explore the maze for 2 minutes and then returned to its home cage. Retention of this learned-task (memory) was estimated $24 \mathrm{~h}\left(15^{\text {th }}\right.$ day) after the first day trial. Significant reduction in TL value of retention indicated improvement in memory.

Y-maze task

This test estimates the short-term memory through the spontaneous alternation behavior [24]. The used Y-maze consisted of three arms (35 cm long, $25 \mathrm{~cm}$ high and $10 \mathrm{~cm}$ wide) and an equilateral triangular central area. Rats were placed at the end of one arm and allowed to move freely through the maze for $8 \mathrm{~min}$. An arm entry was counted 
when the hind paws of the rat were completely within the arm. Spontaneous alternation behavior was defined as entry into all three arms on consecutive choices. The number of maximum spontaneous alternation behaviors was then the total number of arms entered minus 2. The spontaneous alternation (\%) was calculated as (actual alternations/ maximum alternations $) \times 100$. Spontaneous alternation behavior is considered to reflect spatial working memory, which is a form of short-term memory.

\section{Brain's enzymes activity assays}

Supernatant preparation

After the Y-maze behavioral test, rats were decapitated and whole brains were removed. The hippocampal and cortical regions of each rat were carefully excised, weighted and homogenized $(10 \%)$ in ice-cold potassium phosphate buffer $(0,1 \mathrm{M}, \mathrm{pH} 7.4)$. The homogenate was centrifuged at $1000 \mathrm{x} \mathrm{g}$ for $15 \mathrm{~min}$ and the supernatant was used for AChE, SOD and CAT activity assays.

Acetylcholinesterase (AChE) activity assays

The AChE activity of rat brain homogenate was evaluated according to the method of Ellman [27] slightly adapted. In the principle of the reaction, acetylcholinesterase hydrolyzes the substrate ATCI (acetylthiocholine iodide) to thiocholine and acetate, unstained products. Thiocholine in the presence of DTNB (5,5'-dithiobis-2nitrobenzoic acid) gives a yellow product (5-thio-2nitrobenzoate), which allows to follow the kinetics spectrophotometer. For this test, $20 \mu \mathrm{l}$ of homogenate was introduced into each microplate well containing $150 \mu \mathrm{l}$ of phosphate buffer $(0.1 \mathrm{M}, \mathrm{pH} 8), 10 \mu \mathrm{l}$ of ATCI $(14 \mathrm{mM})$ and $10 \mu \mathrm{l}$ of DTNB $(10 \mathrm{mM})$. The appearance of the yellow color is measured at $412 \mathrm{~nm}$ every minute intervals for 5 min using UV/visible spectrophotometer.

Superoxide Dismutase (SOD) activity assays

The activity of superoxide dismutase (SOD) was assayed using the method of Misra and Fridovich [28] with slight modification. It is based on the inhibition of autoxidation of epinephrine to adrenochrome. This oxidation has a very complex chemical mechanism, but several of its steps are $\mathrm{O}_{2} \cdot{ }^{-}$dependent, and thus it can be used for SOD measurement. The rat's brain supernatant 0.5 $\mathrm{ml}$ was added to distilled water $0.8 \mathrm{ml}$, ice cold ethanol 0.25 $\mathrm{ml}$ and chloroform $0.15 \mathrm{ml}$. The mixture was shaken for 5 minutes at $4^{\circ} \mathrm{C}$ and then centrifuged. $0.2 \mathrm{ml}$ of EDTA $(0.6$

$\Delta$

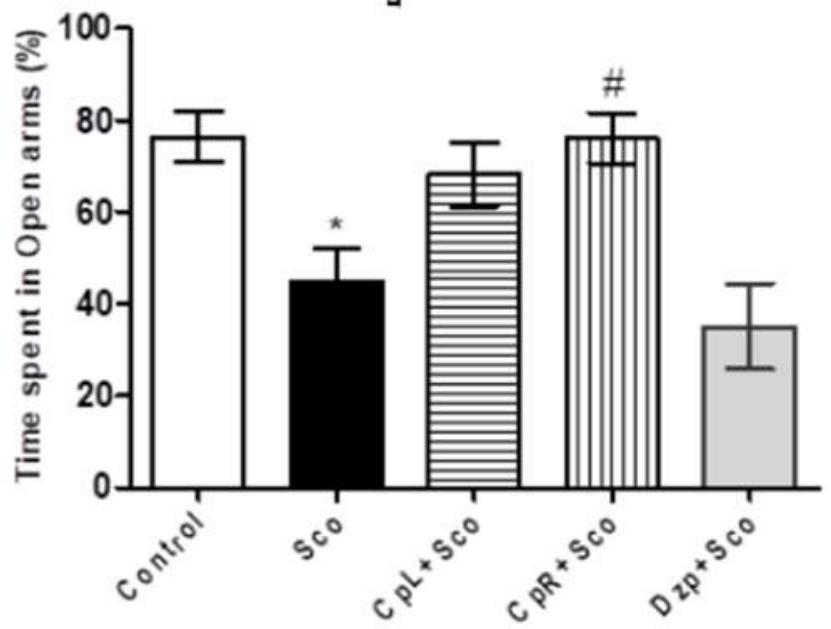

$\mathrm{mM}), 0.4 \mathrm{ml}$ of $\mathrm{Na}_{2} \mathrm{CO}_{3}(0.25 \mathrm{M})$ and $0.2 \mathrm{ml}$ of epinephrine ( $3 \mathrm{mM}$ ) were added to the reaction mixture and the absorbance was measured at $420 \mathrm{~nm}$.

Catalase (CAT) activity assays

The CAT activity was measured according to the method of Beers and Siezer [29]. For this trial, $50 \mu 1$ of rat brain homogenate is introduced into a tube containing 950 $\mu \mathrm{l}$ of phosphate buffer $(50 \mathrm{mM}, \mathrm{pH} \mathrm{7.4)}$. The reaction is initiated by the addition of $500 \mu \mathrm{l}$ of hydrogen peroxide $\left(\mathrm{H}_{2} \mathrm{O}_{2}, 30 \mathrm{mM}\right)$. The control consisted to $1 \mathrm{ml}$ of phosphate buffer and $500 \mu \mathrm{l}$ of hydrogen peroxide $\left(\mathrm{H}_{2} \mathrm{O}_{2}\right)$. The reduction of the optical density (OD) due to the decomposition of the hydrogen peroxide is measured after one minute of incubation at $240 \mathrm{~nm}$. The enzyme activity is expressed as $\mu \mathrm{mol}$ of $\mathrm{H}_{2} \mathrm{O}_{2}$ consumed $/ \mathrm{min} / \mathrm{mg}$ of protein.

\section{Statistical analysis}

Statistical analysis was performed with GraphPad Prism 5.03 for Windows (Graph Pad Software, Inc., California USA), using One-way ANOVA. All results were expressed as the mean \pm S.E.M. Statistical differences were determined by Tukey's post hoc test for multiple intergroup comparisons. Differences were considered significant when the $\mathrm{p}$ value was less than $0.05(\mathrm{p}<0.05)$.

\section{Results and discussion}

\section{Anxiolytic effect of $C$. procera extracts}

The behavior in the elevated plus-maze is mainly used to estimate the anxiety effect of drug. From results, scopolamine treated group (Sco) showed significant decrease $(p<0.05)$ of time spent in open arms as compared to the control group (figure 1A). Likewise, the frequency of entries in open arms also has decreased in scopolamine group (figure 1B). These results indicate an anxiety effect induced by scopolamine on rats. However, animals preadministered with $C$. procera root-bark extract showed significant difference $(\mathrm{p}<0.05)$ of time spent in open arms as compared to the rats of scopolamine treated group (figure 1A). The same profile was observed for the frequency of entries in open arms (figure 1B). These results suggest that the extract inhibited the anxiety effect induced by scopolamine. This assumes that $C$. procera root-bark has an anxiolytic property.

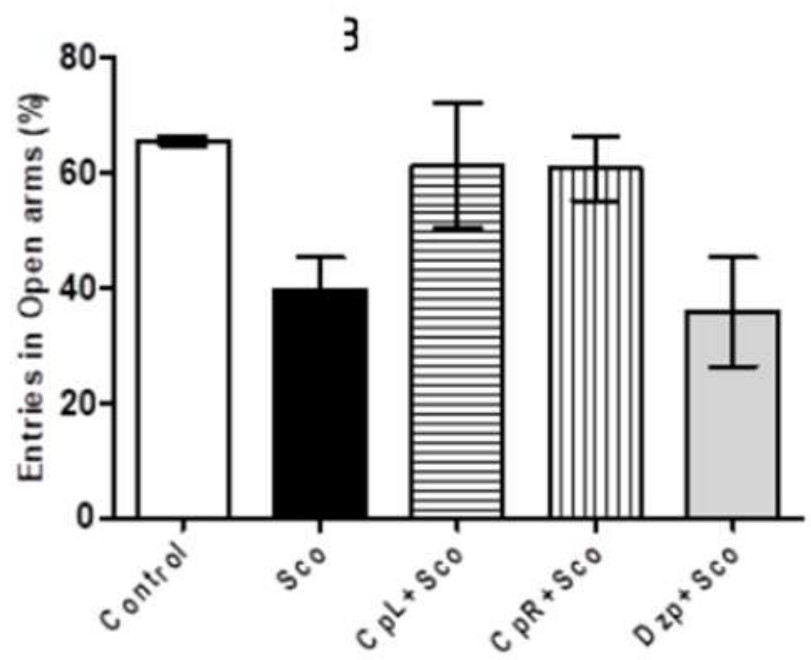

Figure 1. Effect of $C$. procera leaves and root-bark extracts on the Time spent in Open Arms [A], and the frequency of Entries in Open Arms [B] of rats. ${ }^{*} \mathrm{p}<0.05$ compared with control group. ${ }^{*} \mathrm{p}<0.05$ compared with scopolamine group. 


\section{Anti-amnesic effect of $C$. procera extracts}

This activity was assessed in the Y-maze task and the elevated plus maze test. The first trial evaluates the shortterm memory of the animals. From results obtained, the scopolamine group (Sco) showed significant decrease $(\mathrm{p}<$ 0.05 ) of the spontaneous alternation (SA) as compared to the control group. This result indicates a difficulty for animals to remember the arm immediately explored before the current arm (arm from which it is going out), which suggested a short-term memory deficit (amnesia). For the rats pre-administration with $C$. procera root-bark extract $(\mathrm{CpR}+\mathrm{Sco})$, the SA was not changed compared to control group (Figure 1A). This result suggests the root-bark extract inhibit the scopolamine effect on rats.
The memory of rats 24 hours after scopolamine administration was evaluated in the elevated plus maze. The Latency Time (TL) was recorded on the 14th day (30 min after scopolamine treatment) and the $15^{\text {th }}$ day $(24 \mathrm{~h}$ after scopolamine treatment). Animals received scopolamine alone (Sco) showed a significantly increase $(\mathrm{p}<0.01)$ of the TL at the $14^{\text {th }}$ and the $15^{\text {th }}$ day compared to the control group (Figure 1B). These results indicate a memory deficit in these animals the $14^{\text {th }}$ day and persisted after 24 hours. Rats preadministered with root-bark extract significantly $(\mathrm{p}<0.05)$ inhibited TL increase the $15^{\text {th }}$ day.

Results of these two tests suggest root-bark extract have anti-amnesic effect against memory deficit induced by scopolamine. While, leaves extract and diazepam did not influence significantly scopolamine effect.
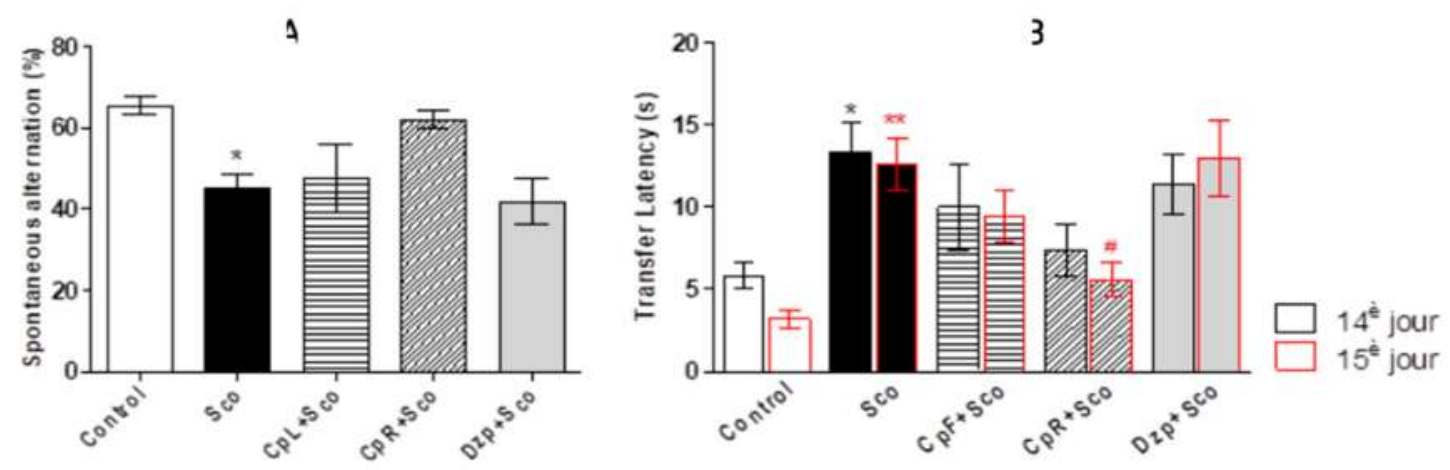

Figure 2. Effect of C. procera leaves and root-bark extracts on Spontaneous Alternation [A], and Transfer Latency [B] of rats. ${ }^{*} \mathrm{p}<0.05,{ }^{*} \mathrm{p}<0.01$ compared with control group. ${ }^{*} \mathrm{p}<0.05$ compared with scopolamine group.

\section{C. procera extracts effects on Brain's enzymes activities}

The AChE specific activity estimated in the rat brain homogenates, revealed no statistical difference $(p>0.05)$ in scopolamine treated groups as compared to control group. Likewise, no difference was observed between profiles of leaves extract group, diazepam group and scopolamine group. However, AChE activity in root-bark treated group kept the same profile as the control group (Figure 2a).

SOD and CAT are very important enzyme able to protect cells and tissues biological integrity against harmful effects of free radicals [30]. Previous studies showed that memory deficit induced by scopolamine affects the stress oxidative parameters and reduce SOD and CAT specific activities [31,32]. In the oxidative evaluation, all animals of groups treated with scopolamine registered SOD and CAT activity lightly decreasing compared to control, except root-bark group. The root-bark extract pretreated group like the control group, presents an opposite profile to that of scopolamine group (Figure 2b, 2c). This observation suggests the extract prevents scopolamine oxidative effect.

These results confirm those observed in behavioral evaluation and certify that root-bark extract has neuroprotective activity. Results of this study corroborate those of Kumar's group who reported the antioxidant and membrane protective activities of $C$. procera root-bark extract [33].
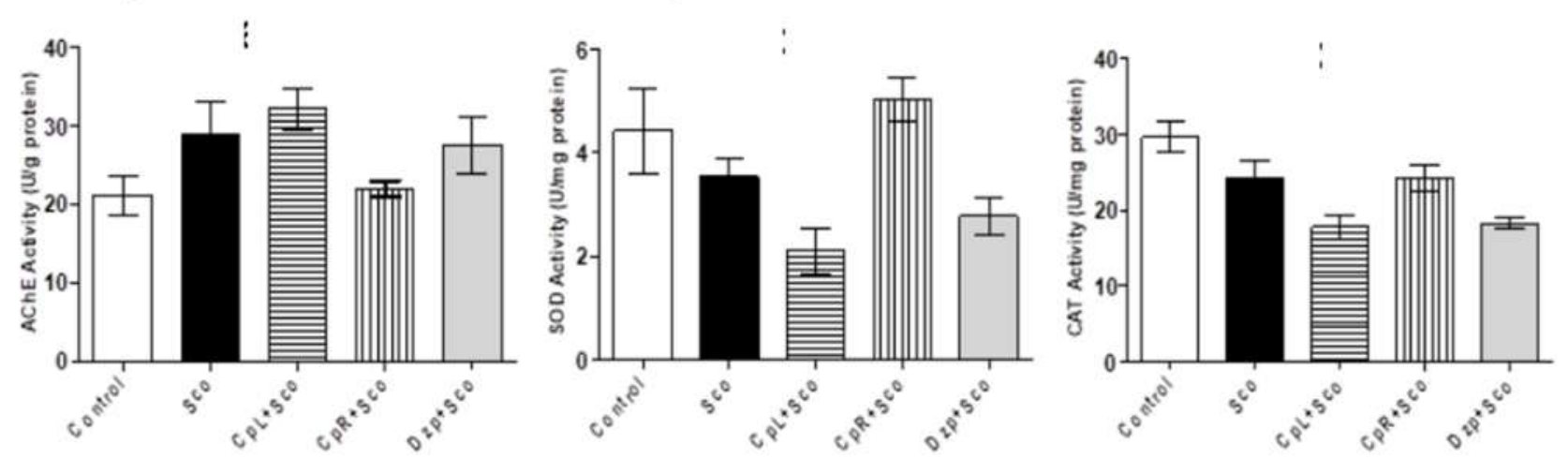

Figure 3. Effect of $C$. procera leaves and root-bark extracts on AChE activity [a], SOD activity [b] and CAT activity [c] in rat's brain. 
Phytochemical compounds have the potential to modulate human metabolism. This potential has various beneficial effects including neurotransmitters modulation and antioxidant properties. These activities step in the prevention of chronic and degenerative diseases [33].

In the anxiolytic assay, results obtained suggest that $C$. procera root-bark extract inhibit the anxiety effect induced by scopolamine. Likewise, the root-bark extract shown antiamnesic effect against memory impairment induced by scopolamine in rats. This anxiolytic and anti-amnesic potential is a good information and might to explain the wide use of this plant for neuropsychiatric diseases treatment in traditional medicine [9,34]. Indeed, some common manifestations of neuropsychiatric and degenerative disorders are anxiety, depression and amnesia [35,36], then all drug which protect against these symptoms contribute necessarily to improve the patient health.

In anti-oxidative tests, $C$. procera root-bark extract presented a profile which suggests that extract prevents scopolamine oxidative effect. Plant-derived antioxidants such as phenolic acids, flavonoids and terpenoids have the potential to delay or protection living organisms from the damage caused by uncontrolled production of free radicals, because of their redox properties $[37,38]$. C. procera was reported to possess these chemicals $[39,40]$, which could support the obtained results.

Epilepsy is a serious neurological disorder which involves the abnormal discharges of electrical activity in the brain cells. The main symptoms of this disease include memory impairment and anxiety [5,41]. Likewise, it was reported that oxidative stress resulting from excessive free-radical generation is implicated in the initiation, development and progression of epilepsy [42].

Previous study recorded that in electroencephalographic evaluation of scopolamine-induced convulsions in fasted mice after food intake, scopolamine administration caused a series of high-voltage polyspikes and fast activity that represents a typical epileptiform manifestation [23]. The study of the relationship between amygdaloid brainstimulation reward and the evolution of seizure activity showed that administration of scopolamine increase the intracranial self-stimulation rate. This result is consistent with the excitatory function of acetylcholine in epileptogenesis [21].

All results of the present study support a protective effect of $C$. procera root-bark extract against behavioral and oxidative disturbance induced by scopolamine in animals. This property could scientifically explain the $C$. procera use for epilepsy treatment in traditional medicine.

As a limitation of the present study, we can mention the lack of a clar validation/verification of the scopolamineinduced model of epilepsy, as this was done before by some previous research groups $[20,21,22,23]$.

\section{Conclusion}

This study reports suggest that $C$. procera provide multiple benefits by reducing the negative health impact of a scopolamine-induced model of epilepsy in rodents, such as anxiety, memory loss and oxidative effect. The root-bark extract showed significant anxiolytic and anti-amnesic effect. While, further investigation is necessary to identify the active compounds responsible of these properties.

\section{Conflicts of Interest}

The authors declare no conflict of interest

\section{References}

1. Organisation Mondiale de la Santé (OMS). Rapport de l'atelier Interrégional de l'OMS sur l'utilisation de la Médecine Traditionnelle dans les soins de santé Primaires; OMS: Genève, Suisse, 2009. (In French).

2. Yasamy M.T., Maulik P.K., Tomlinson M., Lund C., Van Ommeren M., Saxena S. Responsible Governance for Mental Health Research in Low Resource Countries. PLoS Med., 2011, 8, 1-6.

3. World Health Organization (WHO). Mental Health Gap Action Programme: Scaling up Care for Mental, Neurological, and Substance Use Disorders; WHO: Geneva, Switzerland, 2008.

4. Moshi, M.J.; Kagashe, G.A.B.; Mbwambo, Z.H. Plants used to treat epilepsy by Tanzanian traditional healers. J. Ethnopharmacol., 2005, 97, 327-336.

5. Butler C.R., Zeman A.Z. Recent insights into the impairment of memory in epilepsy: transient epileptic amnesia, accelerated long-term forgetting and remote memory impairment. Brain, 2008, 131: 2243-2263.

6. Bhattacharjee A., Shashidhara SC., Saha S. Neuroprotective Activity of Crataeva nurvala BuchHam Stem Bark against Scopolamine Induced Cognitive Impairment via Antioxidative Activities in Rats. American Journal of Ethnomedicine, 2014, Vol. 1(6): 371-383.

7. McGregor AL., Dysart J., Tingle MD., Russell BR., Kydd RR., Finucane G. Varenicline improves motor and cognitive symptoms in early Huntington's disease. Neuropsychiatric Disease and Treatment, 2016, 12: 2381-2386.

8. Parihar, G. \& Balekar, (2016). Calotropis procera: A phytochemical and pharmacological review. TJPS, 40 (3), 115-131.

9. Kinda PT, Zerbo P, Guenné S, Compaoré M, Ciobica A, Kiendrebeogo M. Medicinal plants used for neuropsychiatric disorders treatment in the Hauts Bassins Region of Burkina Faso. Medicines 2017; 4(32): 21.

10. Bairagi SM., Ghule P., Gilhotra R. Pharmacology of Natural Products: An recent approach on Calotropis gigantea and Calotropis procera. Ars Pharmaceutica, 2018, 59(1): 37-44.

11. Mainasara MM, Aliero BL, Aliero AA, Dahiru SS. Phytochemical and antibacterial properties of Calotropis procera (Ait.) R. Br. (Sodom apple) fruit and bark extracts. IJMB 2011; 1(1): 8-11.

12. Nenaah, G.E. Potential of using flavonoids, latex and extracts from Calotropis procera (Ait.) as grain protectants against two coleopteran pests of stored rice. Ind. Crop. Prod. 2013, 45: 327-334.

13. Taïwe GS, Kuete V. Neurotoxicity and neuroprotective effects of African medicinal plants. Toxicological survey of African medicinal plants. New Delhi: Elsevier; 2014, p. 423-444.

14. Al-Snafi AE. The constituents and pharmacological properties of Calotropis procera-an overview. Int $\mathbf{J}$ Pharm Rev Res 2015; 5: 259-275. 
15. Flood J.F, Cherkin A. Scopolamine effects on memory retention in mice: A model of demencia? Bihavioral and neural Biology, 1986; 45(2): 169-184.

16. Broks P., Preston G.C., Traub M., Poppleton P., Ward C. Stahl S.M. Modelling dementia: effects of scopolamine on memory and attention. Neuropsychologia, 1988; 26(5): 685-700.

17. Foyet H.S, Abaïssou H.H.N., Wado E., Acha E.A., Ciobica A. Emilia coccinae (SIMS) G Extract improves memory impairment, cholinergic dysfunction, and oxidative stress damage in scopolamine-treated rats. BMC Complementary and Alternative Medicine, 2015; 15: 333.

18. Balmus I-M., Ciobica A. Main Plant Extracts' Active Properties Effective on Scopolamine-Induced Memory Loss. American Journal of Alzheimer's Disease \& Other Dementias, 2017; 32(7): 418-428.

19. Yadang F.S.A., Nguezeye Y., Kom C.W., Betote P.H.D., Mamat A., Tchokouaha L.R.Y., Taiwé G.S., Agbor G.A., Bum E.N. Scopolamine-Induced Memory Impairment in Mice: Neuroprotective Effects of Carissa edulis (Forssk.) Valh (Apocynaceae) Aqueous Extract. International Journal of Alzheimer's Disease, 2020; 10p.

20. Strom B.L., Carson J.L., Schinnar R., Snyder E.S., Shaw M., Waiter S.L. No causal relationship between transdermal scopolamine and seizues: Methodologic lessons for pharmacoepidemiology. Clin Pharmacol Ther, 1991; 50:107-113.

21. Brophy P.D., Borowski T.B. Kokkinidis L. Effects of Scopolamine on the Rewarding and Seizure-Inducing Properties of Amygdaloid Stimulation. Pharmacology Biochemistry and Behavior, 1993; 44: 425-428.

22. Enginar N., Yamanturk P., Nurten A., Koyuncuoglu H. Scopolamine-induced convulsion in food given fasted mice: effects of clonidine and tizanidine. Epilepsy Research, 1999; 35(2): 155-160.

23. Nurten A., Ozen I., Karamursel S., Kara I. Electroencephalographic characterization of scopolamineinduced convulsions in fasted mice after food intake. Seizure, 2006; 15: 509-519.

24. Hritcu L, Bagci E, Aydin E, Mihasan M, Antiamnesic and antioxidants effects of Ferulago angulata essential oil against scopolamine-induced memory impairment in laboratory rats. Neurochem Res., 2015; 40: 1799- 1809.

25. Foyet, H.S., Hritcu, L., Ciobica, A., Stefan, M., Kamtchouing, P. \& Cojocaru D. (2011). Methanolic extract of Hibiscus asper leaves improves spatial memory deficits in the hydroxydopamine-lesion rodent model of Parkinson's disease. Journal of Ethnopharmacol., 133, 773-779.

26. Joshi, H. \& Parle, M. (2007). Evaluation of the antiamnesic effects of Phyllanthus amarus in mice. Colomb Med., 38(2), 132-139.

27. Ellman GL, Courtney KD, Andres V, Feathe-Stone RM. A new and rapid colorimetric determination of acetylcholinesterase activity. Biochem Pharmacol., 1961; 7: 88-95.

28. Misra HP, Fridovich I. The role of superoxide anion in the autoxidation of epinephrine and a simple assay for superoxide dismutase. J Biol Chem., 1972; 247(10): 3170-3175.

29. Beers F, Sizer JR. Cambridge, a spectrophotometric method for measuring the breakdown of hydrogen peroxide by catalase. J Biol Chem., 1951; 195: 133-140.

30. Otitoju, O., Onwurah, I.N.E., Otitoju, G.T.O., Ugwu, C.E. (2008). Oxidative stress and superoxide dismutase activity in brain of rats fed with diet containing permethrin. Biokemistri., 20(2), 93-98.

31. Jawaid, T., Shakya, A.K., Siddiqui, H.H. \& Kamal, M. (2014). Evaluation of Cucurbita maxima Extract against Scopolamine-Induced Amnesia in Rats: Implication of Tumour Necrosis Factor Alpha. Z. Naturforsch., 69c, 407-417.

32. Bagci E, Aydin E, Mihasan M, Maniu C, Hritcu L. Anxiolytic and antidepressant-like effects of Ferulago angulata essential oil in the scopolamine rat model of Alzheimer's disease. Flavour Fragr J., 2015; 31: 70-80.

33. Kumar S., Gupta A., Pandey A.K. Calotropis procera Root Extract Has the Capability to Combat Free Radical Mediated Damage. ISRN Pharmacology, 2013, p.8.

34. Auditeau E., Chassagne F., Bourdy G., Bounlu M., Jost J., Luna J., Ratsimbazafy V., Preux P-M., Boumediene F. Herbal medicine for epilepsy seizures in Asia, Africa and Latin America: a systematic review. Journal of Ethnopharmacology, 2019, 234: 119-153.

35. Isaac M.L., Larson E. Medical Conditions with Neuropsychiatric Manifestations. Med Clin N Am., 2014, 98: 1193-1208.

36. Marson F., Lasaponara S., Cavallo M. A Scoping Review of Neuromodulation Techniques in Neurodegenerative Diseases: A Useful Tool for Clinical Practice?. Medicina, 2021, 57(215), 23p.

37. Govindarajan R., Vijayakumar M., and Pushpangadan P. Antioxidant approach to disease management and the role of 'Rasayana' herbs of Ayurveda. Journal of Ethnopharmacology, 2005, 99(2): 165-178.

38. Sridevi P., Budde S., Neeraja T., Bhagavan R.M., Adap D. Anti-Oxidants and their Role in Disease Management. Int. J. Med. Res. Health Sci. 2018, 7(3): 175-190.

39. Garabadu D., Srivastava N., Murti Y. Calotropis procera attenuates chronic unpredictable mild stressinduced depression in experimental animals. Metabolic Brain Disease, 2019, 34:1635-1647.

40. Kinda P.T., Nacoulma A.P., Guenné S., Compaoré M., Djandé A., Lagnika L., Kiendrébéogo M. The Metabolomic study of Calotropis procera Ait. from Burkina Faso, based on chemical functional groups profiling using FTIR. Journal of Complementary and Integrative Medicine, 2020, 20190134, 9p.

41. Hingray C., McGonigal A., Kotwas I., MicoulaudFranchi J-A. The Relationship Between Epilepsy and Anxiety Disorders. Current Psychiatry Reports, 2019, 21(40): 1-13.

42. Rohilla A., Kalra S., Singh G., Jain J. Oxidative stress and epilepsy: a review. European Journal of Pharmaceutical and Medical Research, 2016, 3(10), 416-423. 